\title{
Characterization of Crude Oil, Asphaltenes Based on Bismuth (Bi), Thorium (Th) and Uranium (U) Levels: Potential Environmental Impact
}

\author{
Amr Abd Elhameed ${ }^{*}$, Avin Pillay ${ }^{1}$, Roger Nunn², Sasi Stephen ${ }^{1}$ \\ ${ }^{1}$ Department of Chemistry, The Petroleum Institute, Abu Dhabi, UAE \\ ${ }^{2}$ Department of Communication, The Petroleum Institute, Abu Dhabi, UAE \\ Email: *aaelhameed@pi.ac.ae, *apillay@pi.ac.ae
}

Received 19 January 2016; accepted 19 February 2016; published 22 February 2016

Copyright (C) 2016 by authors and Scientific Research Publishing Inc.

This work is licensed under the Creative Commons Attribution International License (CC BY). http://creativecommons.org/licenses/by/4.0/

(c) (i) Open Access

\section{Abstract}

The actinides ( $\mathrm{Th}, \mathrm{U}$ ) and bismuth exist at ultra-trace levels in petroleum and have rarely been reported to characterize combustible fuels. However, high-performance mass spectrometry coupled with plasma technology has succeeded in reaching detectable limits in the $\mathrm{ng} / \mathrm{L}$ range, and has thus made such characterization possible. Crude oil is used as sludge for certain agricultural purposes; and asphaltenes are converted to by-products for constructing car parks, pavements, roofing material and thoroughfares. Our study uncovers an area that has not been previously explored and we examine the potential ecotoxicology of bismuth, thorium and uranium in this context. Asphaltene derivatives were separated from crude oil samples via multiple-stage soxhlet extraction. The virgin crude oil and isolated asphaltenes were investigated for $\mathrm{Bi}$, Th and $\mathrm{U}$ content using a high-powered hyphenated facility. A Perkin Elmer SCIEX DRC-e ICP coupled to a quadrupole mass spectrometer was employed to detect the elements of interest. The levels of these elements occurred in the $\mathrm{mg} / \mathrm{L}(\mathrm{ppm})$ and $\mu \mathrm{g} / \mathrm{L}(\mathrm{ppb})$ ranges and were compared for crude oil and asphaltenes. The data showed higher levels of the detected elements in the asphaltene phase. The feasibility of applying the experimental results as a fingerprinting tool for provenancing crude oil and asphaltenes was examined. The results are discussed from the perspective of bismuth and actinide pollution and its long-term impact on sustainable development.

\section{Keywords}

Bismuth, Thorium, Uranium, ICP-MS, Crude Oil, Asphaltenes

\footnotetext{
${ }^{*}$ Corresponding authors.
}

How to cite this paper: Elhameed, A.A., Pillay, A., Nunn, R. and Stephen, S. (2016) Characterization of Crude Oil, Asphaltenes Based on Bismuth (Bi), Thorium (Th) and Uranium (U) Levels: Potential Environmental Impact. Journal of Environmental Protection, 7, 190-197. http://dx.doi.org/10.4236/jep.2016.72017 


\section{Introduction}

Bismuth, thorium and uranium occur naturally at ultra-trace levels in soils, rocks and geochemical formations [1] [2]. Their presence in crude oil is as a result of leaching from subterranean rock formations and reservoirs [3]. The environmental impact of these elements is relatively underexplored due to the lack of suitably sensitive instrumentation to detect them. The advent of ICP-MS technology, however, has facilitated measurement of these heavy metals. Of significance is that all three of them possess relatively long-lived radioisotopes that are embedded in the earth's crust. The health effects relating to these metals of interest depend on how widely humans are exposed to them. In the case of soils, they are usually confined to agricultural areas so human exposure is limited. However, crude oil in the form of sludge is used as a soil-conditioner on land farms [4] [5] and asphaltenes are converted into material for constructing roads, paving for malls, roofing and car parks [6] [7]. Human exposure to the converted forms of crude oil and asphaltenes is, therefore, much wider than expected. Low-level chronic pollution could result, necessitating investigation of the potential environmental effects [4].

The most critical threat that bismuth and these particular actinides can present is pollution of aquatic resources and underground water supplies. Most oil producing countries are arid and there is a chronic water shortage in many of these regions [8] [9]. Contamination of water supplies by toxins of this nature would be highly deleterious to the environment and would seriously affect sustainability. Sustainable development refers to growth of our planet in all forms so that humans and other organisms can survive and possess a high quality of life [10] [11]. Any trace of such pollution could pose a threat to sustainability [12]. The main objective of this study was to investigate the levels of bismuth, thorium and uranium in crude oil and asphaltenes and explore their potential impact on the environment. Possible use of our results as a "fingerprinting” tool and the feasibility of "mining" crudes and asphaltenes for these metals are novel aspects that have emerged from this work.

\section{Material and Methods}

\subsection{Soxhlet Extraction/ICP}

Asphaltene phases were isolated from crude oil samples using multiple soxhlet distillation [13]. Solubility and density parameters $(\sim 1.13-1.20 \mathrm{~g} / \mathrm{mL})$ validated the abstracted asphaltene fractions [14]. Elemental detection (Bi, Th, U) was achieved with a Perkin Elmer SCIEX DRC-e ICP_-which combines a high temperature plasma, generated and maintained by an RF source and an inductance coil-coupled to a high-performance mass spectrometer [7]. Argon gas flows out of the plasma torch leading to the formation of high speed Ar ions that oscillate in alternate electric and magnetic fields, creating a chain of collisions and maintaining a continuous discharge or plasma at a temperature of 6000 - $8000 \mathrm{~K}$. The nebulizer gas flow was $0.80 \mathrm{~L} / \mathrm{min}$.

\subsection{Quadrupole Mass Filter}

The quadrupole mass filter isolates ions and consists of four rods made of molybdenum (Figure 1). The opposite pairs of rods are supplied with AC and DC voltages and the voltages are rapidly switched in combination with an RF field [7]. This results in a sequentially changing electrostatic field which allows only ions of a single mass-to-charge ratio (m/e) to pass through the filter at a given instant in time. Even though the switching and the mass selection process is sequential, this happens at a very rapid rate so that the quadrupole mass filter can separate up to $2400 \mathrm{amu}$ (atomic mass units) per second, making it an ultra-sensitive instrument for multi elemental analysis. The ICP-MS was standardized with certified solutions (Fluka 70007; 10.00 ppb per element). Repeatability produced relative standard deviations $<5 \%$ indicating that the system's performance was satisfactory (Table 1). An internal standard was used to adjust any minor perturbations due to instrumental drift. Samples and standards were prepared in mild acidic aqueous solutions. The software played a major role in background correction and eliminating matrix effects. The technique is highly sensitive compared to other analytical techniques [15]-[20].

\section{Results and Discussion}

\subsection{Elemental Profiles}

Bismuth, thorium and uranium have some relatively long-lived radioactive isotopes that occur naturally in the earth's crust [1]. In the case of bismuth, Bi-209 was considered to be stable until 2003, when it was found to 


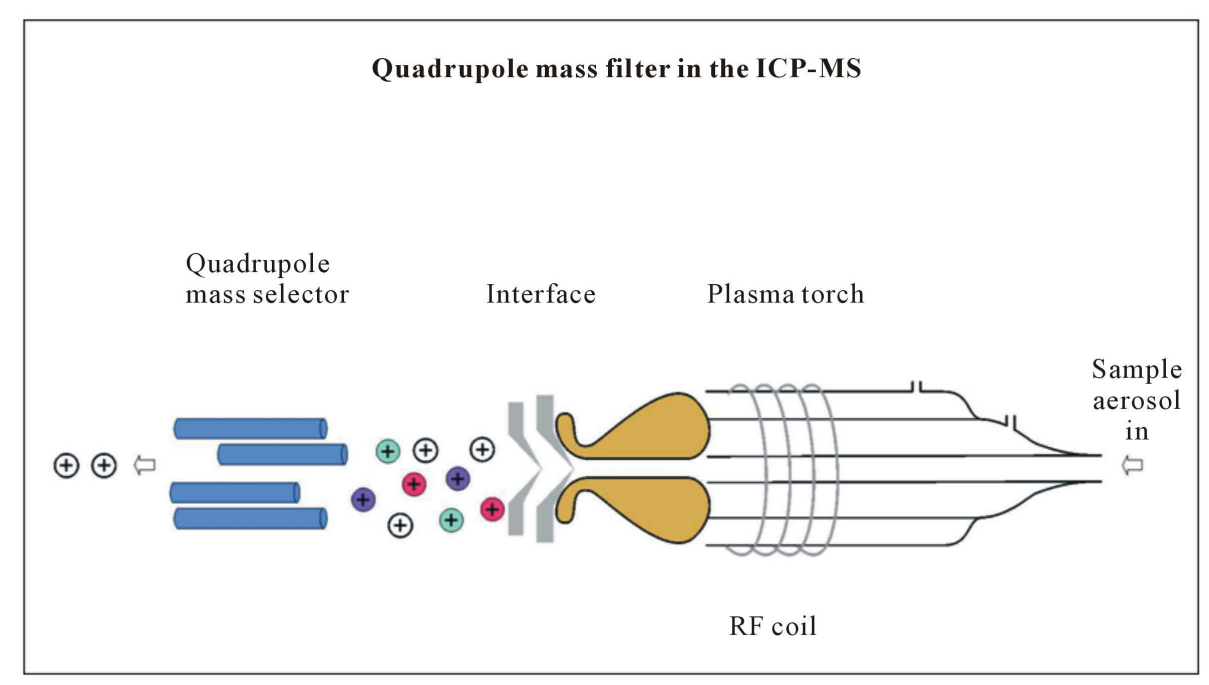

Figure 1. Quadrupole mass filter in the ICP-MS.

Table 1. Repeatability test of the ICP-MS for various elements $(\mu \mathrm{g} / \mathrm{L})$ in an aqueous standard showing the mean, standard deviation (SD) and relative standard deviation (SD\%).

\begin{tabular}{ccccccc}
\hline Element & Trial \#1 & Trial \#2 & Trial \#3 & Mean & SD & SD \% \\
\hline V & 10.01 & 9.36 & 9.82 & 9.73 & 0.33 & 3.43 \\
Cr & 9.51 & 10.04 & 10.07 & 9.87 & 0.32 & 3.19 \\
Mn & 9.59 & 10.06 & 10.21 & 9.95 & 0.32 & 3.25 \\
Co & 10.54 & 9.82 & 10.12 & 10.16 & 0.36 & 3.56 \\
Ni & 10.08 & 9.46 & 9.56 & 9.70 & 0.33 & 3.43 \\
As & 9.82 & 10.21 & 9.74 & 9.92 & 0.25 & 2.53 \\
Se & 9.78 & 9.59 & 9.61 & 9.66 & 0.10 & 1.08 \\
Mo & 9.89 & 9.14 & 9.72 & 9.58 & 0.39 & 4.10 \\
Cd & 9.51 & 10.06 & 10.09 & 9.89 & 0.33 & 3.30 \\
Tl & 9.59 & 9.65 & 10.21 & 9.82 & 0.34 & 3.48 \\
Th & 9.85 & 10.28 & 9.42 & 9.85 & 0.43 & 4.37 \\
U & 10.08 & 9.65 & 10.12 & 9.95 & 0.26 & 2.62 \\
\hline
\end{tabular}

have a half-life of about $2 \times 10^{19}$ years [1]. Thorium has one partially stable isotope, Th-232, with a half-life of about $2 \times 10^{6}$ years. And uranium has two relatively stable isotopes U-238 (half-life, $5 \times 10^{9}$ years) and U-235 (half-life, $7 \times 10^{8}$ years), of which U-238 predominates in nature [1]. The elemental profiles of each of these elements in crude oil and asphaltene samples are discussed below.

Bismuth $(\mathrm{Z}=83)$ : Investigating bismuth levels in petroleum has not been previously documented. The profile in Figure 2 shows that bismuth is highly concentrated in the asphaltene fractions. This pattern is consistent with crude oil samples displaying much lower levels. Comparison between the levels in crude oil and asphaltene samples reveals that concentrations differ by about a factor of fifty in some cases. Bi levels in soil are roughly 1 - $10 \mu \mathrm{g} / \mathrm{kg}(1-10 \mathrm{ppb})$, and, in surface ocean waters, about $0.5 \mu \mathrm{g} / \mathrm{L}(0.5 \mathrm{ppb})$. The levels in potable water are not known, and could possibly be surmised to be below $0.1 \mathrm{ppb}$. The maximum concentration in our asphaltenes is about $65 \mathrm{mg} / \mathrm{L}$ (65 ppm), which is extremely elevated. These abnormal levels could have a significant impact on the environment and create an unwanted threat, especially to water supplies. The bismuth itself originates from source rock and underground formations in contact with the crude. It is usually present in the sulphide and 


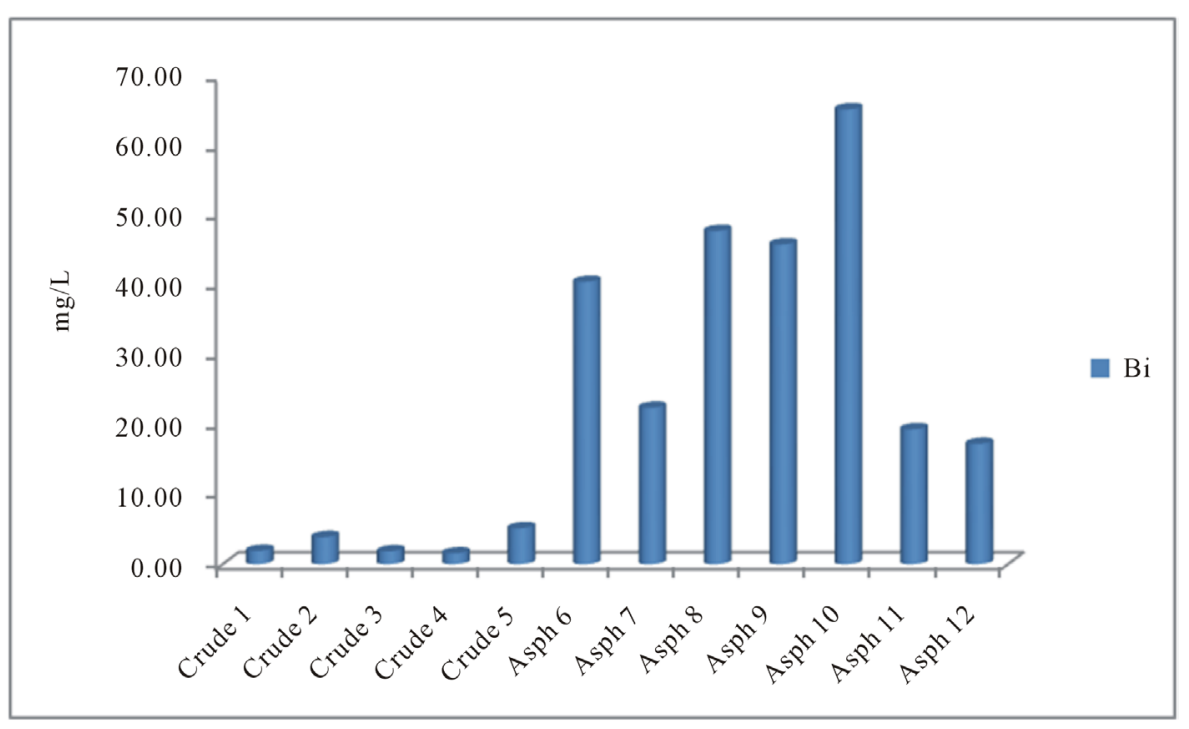

Figure 2. Bismuth levels in crude oil and asphaltene samples.

oxide forms. The data in our previous papers [6] [7] suggest that metals tend to concentrate in the asphaltene phase, perhaps at the point of separation. According to Figure 2, the maximum level in crude oil is roughly 5 $\mathrm{mg} / \mathrm{L}$, which is also above expected levels. It is interesting to note that the levels in the asphaltene samples vary widely in the range $20-70 \mathrm{mg} / \mathrm{L}$, and the range in crude oil is roughly $2-6 \mathrm{mg} / \mathrm{L}$. The reason for this wide variation is not clear and could be due to uneven leaching of source rock. These elevated levels could be useful in diagenetic studies to provide important clues in geochemical mechanisms [3].

Thorium $(Z=90)$ : The environmental impact of thorium in petroleum products has not been widely reported and is one of the essential features of this study. The general profile of thorium (Figure 3) differs from that of bismuth, in that some crude oil samples display higher levels than the asphaltene samples. This particular "anomaly" is present only in the profile of this element-and is conspicuously absent in those for Bi and U. Thorium is present in the earth's mantle mainly in the form of phosphates (monazite), and the metal has pronounced allotropic forms, some of which could have a stronger affinity for crude oil than the asphaltene phase [7]. This allotropic feature, therefore, could possibly be attributed to greater retention in crude oil (in some cases) when the asphaltenes are separated. Thorium occurs in soil at levels between $1-10 \mathrm{mg} / \mathrm{kg}$. The levels presented in Figure 3 are within the expected range, except for a single asphaltene sample, which reflects a level slightly above 20 $\mathrm{mg} / \mathrm{L}$. According to Figure 3, the maximum level in crude oil is roughly $10 \mathrm{mg} / \mathrm{L}$, which is at the limit of expected levels. Of interest, is that the levels in the asphaltene samples vary roughly in the range $2-20 \mathrm{mg} / \mathrm{L}$, and the range in crude oil is roughly $1-10 \mathrm{mg} / \mathrm{L}$. Such variations are appreciable and cannot be used to either characterize or identify asphaltenes or crude based on thorium concentrations. However, this fluctuation in levels signifies irregular leaching of the earth's crust (as in the case of bismuth) [3].

Uranium ( $\mathrm{Z}=92)$ : U-238 and U-234 are "primordial" isotopes of uranium and predominate in nature [1]. A comparison between the levels in crude oil and asphaltene samples (Figure 4) indicates that uranium concentrations in the asphaltene fractions are relatively higher, with depletion to levels below $0.50 \mathrm{mg} / \mathrm{L}$ in crude. This trend is similar to the one encountered in Figure 2 for Bi. However, the experimentally determined levels of uranium are much lower in comparison with the Bi levels. Uranium concentration in soils is about $2 \mathrm{mg} / \mathrm{kg}$, which is in the region of the detected levels in asphaltenes. There is no evidence of elevated concentrations in the asphaltene samples, and the range is comparatively narrow, varying between $1-3 \mathrm{mg} / \mathrm{L}$. The levels in the crude oil samples are not wide either, and vary between $0.2-0.5 \mathrm{mg} / \mathrm{L}$. Seawater contains about $3.3 \mu \mathrm{g} / \mathrm{L}$ of uranium and is considered to be a useful source of uranium. Of the three elements studied here the most diminished range for asphaltenes is encountered in uranium. This suggests that asphaltene samples could possibly be identified on the basis of their uranium concentration. Clearly in Figure 4, most of the asphaltene concentrations fall between $1.0-1.5 \mathrm{mg} / \mathrm{L}$, and this range could be used for purposes of characterization. Of course, outliers will occur, as seen in Figure 4, but the data suggest that in the majority of cases it may be possible to distinguish asphaltene samples on the basis of their uranium levels. 


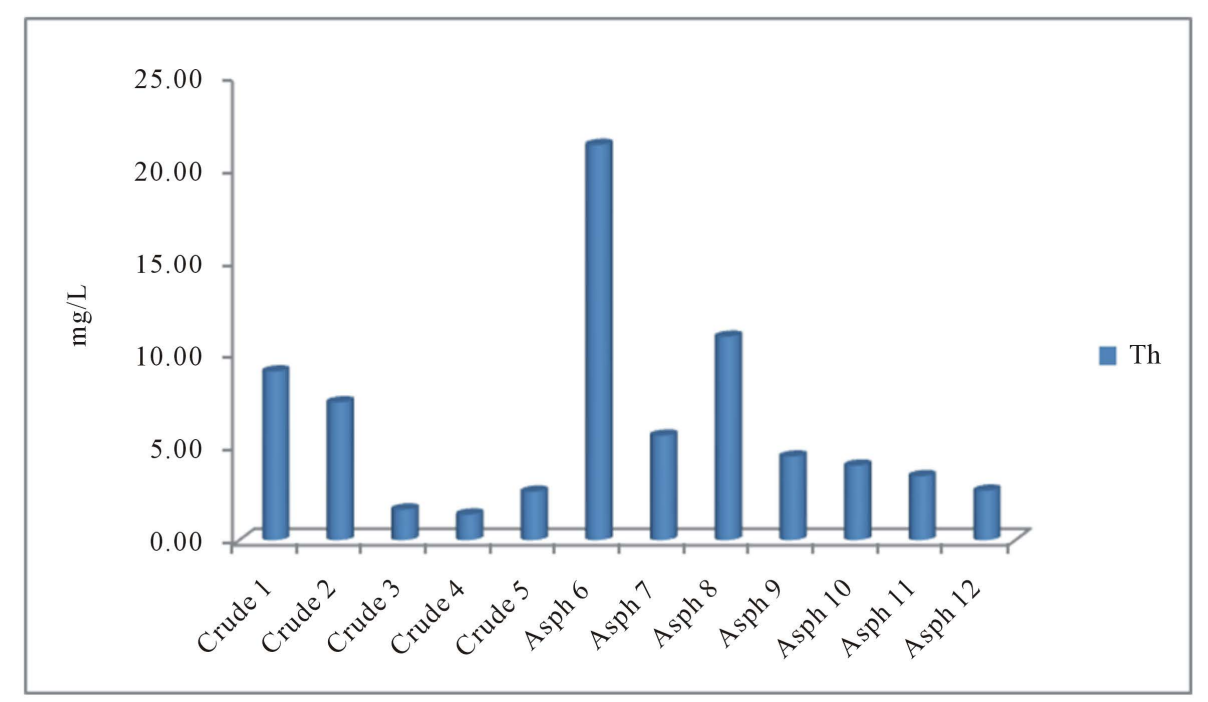

Figure 3. Thorium levels in crude oil and asphaltene samples.

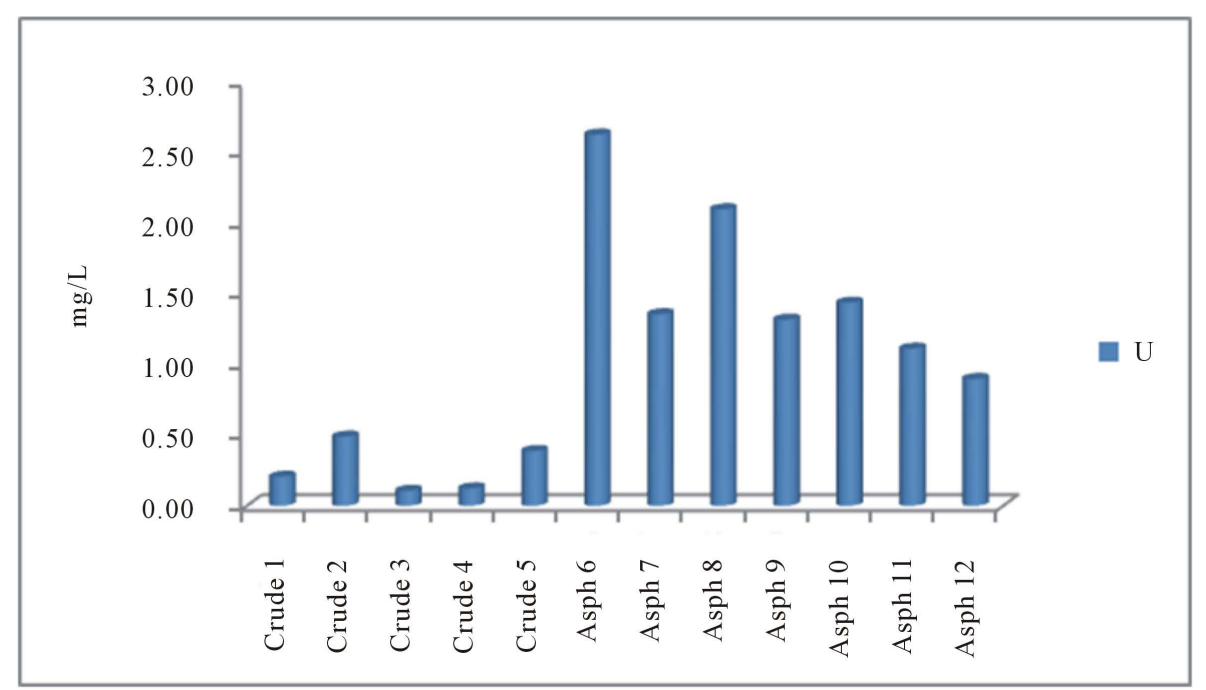

Figure 4. Uranium levels in crude oil and asphaltene samples.

\subsection{Fingerprinting Tool}

The novelty that emerges from this work is the possibility of using the foregoing data as a "fingerprinting" tool to identify crudes and asphaltenes. It is well known that $\mathrm{Ni} / \mathrm{V}$ ratios are used to characterize asphaltenes and are employed in "fingerprinting" studies [7]. Of significance, is that "fingerprinting" is linked to provenancing [21], so the primary purpose of employing such ratios is to identify the source and location of the asphaltenes. It is acknowledged that Ni/V ratios could be used to identify the oil field linked to the asphaltene specimen [7]. However, the problem is that if there is nickel contamination from the pipeline these ratios are not reliable. It is therefore, necessary to seek more reliable parameters devoid of contamination. Figure 5 depicts plots of $\mathrm{Bi} / \mathrm{Th}$, $\mathrm{Bi} / \mathrm{U}$ and $\mathrm{Th} / \mathrm{U}$ concentration ratios, for each sample, to determine whether some trend or pattern exists to identify or "fingerprint" asphaltenes or crude oil on the basis of elemental content. It is clear from Figure 5 that the $\mathrm{Bi} / \mathrm{U}$ ratios are widely scattered, which makes this particular ratio ineffective for use as a fingerprinting tool. However, careful inspection of Figure 5 reveals that $\mathrm{Bi} / \mathrm{Th}$ ratios for crude oil samples are more or less consistent (encircled) and based on these data it is feasible that $\mathrm{Bi} / \mathrm{Th}$ ratios in the range 0.5 - 1 could be used to "fingerprint" crude oil. On the other hand, in the case of asphaltenes, the experimental results associated with $\mathrm{Th} / \mathrm{U}$ ratios in Figure 5 (encircled) are equally consistent and suggest that it is equally feasible to employ these ratios 


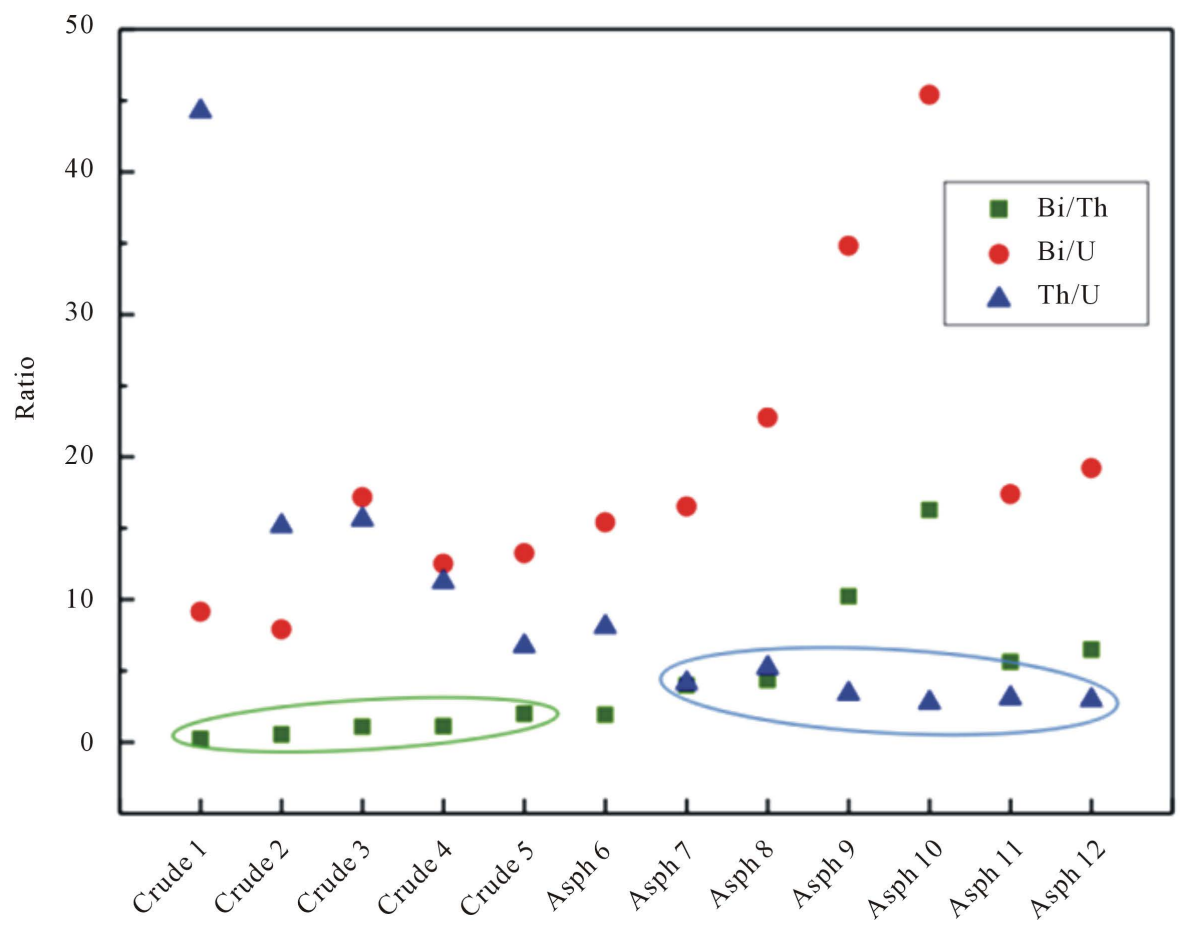

Figure 5. Plots showing Bi/Th, Bi/U and Th/U ratios for "fingerprinting”.

to "fingerprint" asphaltenes. Th/U ratios could be used as a possible alternative to $\mathrm{Ni} / \mathrm{V}$ ratios and are widely impervious to contamination from general sources such as pipelines and chemical treatment. $\mathrm{Th} / \mathrm{U}$ ratios in the range 3 - 5 could characterize the asphaltene samples of interest. A point to stress is that previously these ratios were not available because measuring devices for detection were not adequately sensitive. However, as aforementioned, ICP-MS performs at ultra-sensitive levels and makes "fingerprinting" of this nature possible.

\subsection{Environmental Impact}

The environmental effects of bismuth, thorium and uranium in crudes and asphaltenes are obscure largely because little or no work has been done in this area, mainly due to the lack of sensitive instrumentation (as aforementioned) [2]. The data in Figures 2-4 show without doubt that the levels of Bi are highly elevated. Collectively, the physiological effects and bio-distribution of Bi are the subject of continued research [22]. However, it is known that $\mathrm{Bi}$ at elevated levels could affect the liver and kidneys. Abnormal levels of toxins in crude oil and asphaltenes could reach water resources through constant leaching and run-off. Water pollution is a major global concern and clean drinking water is in short supply in many oil producing countries. Although thorium and uranium levels in Figure 3 and Figure 4 are comparable with those in soil, asphaltenes and crude oil in converted forms (such as sludge and road materials) tend to be associated with wider human exposure, and contamination of water supplies poses the most serious hazard. Like bismuth, thorium poisoning is under considerable investigation [22], but it has come to light that ingested thorium at raised levels could bind to protein responsible for transporting iron in blood, and thus affect the liver, kidneys and bones. The main health effect with elevated uranium is kidney toxicity. These metals are naturally occurring and have long-lived radioisotopes; therefore, radiological effects from all three elements could present a potential long-term hazard [22]. Constant ingestion of low-level radiation (especially alpha particles) from water pollution could result in chronic physiological and dermal disorders. Depletion of these metals in crudes and asphaltenes is therefore, essential and could have mutually beneficial effects, as discussed below.

\section{4. "Mining" Asphaltenes and Crude Oil}

Asphaltenes are enriched in $\mathrm{Bi}$ and the foregoing data (Figure 2) suggest that asphaltenes could be a good 
source of bismuth. The feasibility of "mining” asphaltenes for bismuth could be a more attractive prospect than extracting bismuth from ores, which have to be mined from the earth's crust prior to chemical treatment. Asphaltenes are easily digested in toluene, which could facilitate abstraction of the elemental bismuth. Bismuth, mixed with other metals to form alloys, has its uses in electronics and fire detection systems. Even though the data in Figure 3 and Figure 4 indicate that there is hardly any enrichment of Th and U in asphaltenes, the fact that asphaltenes are soluble in toluene [7] could also facilitate simultaneous extraction of these elements via chemical methods. Thorium is of considerable benefit in the optical industry, and, in addition, by being mined from asphaltenes could also be extracted from crude. Uranium could be used in industry as ballasts for ships and aircraft. The prospect of thus mining asphaltenes and crudes for these metals has a dual benefit. In this way, these fuels will be depleted of heavy metals that could pose a potential risk to the environment, while at the same time there is a commercial gain from marketing the metals that are removed.

\section{Conclusion}

The development of our research produced two novel features: i) the use of bismuth and actinide ratios as potential fingerprinting tools; and ii) the prospect of "mining” enriched asphaltenes and crudes for $\mathrm{Bi}$, Th and U. The latter could lead to reduced environmental effects, which could be potentially significant, especially if the asphaltenes in converted forms are exposed to the environment. The most critical threat is that of water contamination, which can be avoided by chemical treatment and demetallisation of these combustible fuels prior to deploying them for construction and other purposes.

\section{Acknowledgements}

The authors wish to thank the Petroleum Institute for financial support.

\section{References}

[1] Chang, R. and Goldsby, K. (2010) Chemistry. 11th Edition, Mcgraw Hill, New York.

[2] Athar, M. and Vohra, S.B. (2001) Heavy Metals and the Environment. New Age International Publishers, New Delhi.

[3] Ghosh, B., Pillay, A.E., Senthilmurugan, B., Kundu, S. and Stephen, S. (2010) Application of Ablative Laser DepthProfiling (ICP-MS) to Probe Diagenetic Information Linked to Secondary Mineral Deposition in Carbonate Reservoir Rock, (Part 2). Canadian Journal of Pure \& Applied Sciences, 4, 1267-1274.

[4] Pillay, A.E., Salih, F.M. and Jayasekara, K. (2005) Low-Level ${ }^{214} \mathrm{~Pb}$ and ${ }^{214} \mathrm{Bi}$ Contamination of Oily Sludge for Use in Road Building and Soil Enrichment. International Journal of Environmental Studies, 62, 571-578. http://dx.doi.org/10.1080/00207230500196070

[5] Taha, R., Ba-Omar, M., Pillay, A.E., Roos, G. and Al-Hamdi, A. (2001) Recycling of Petroleum-Contaminated Sand. Journal of Environmental Monitoring, 3, 417-420. http://dx.doi.org/10.1039/b103750c

[6] Elhameed, A.A., Pillay, A.E., Nunn, R. and Stephen, S. (2015) Comparative Study of Toxic Speciation $\left[\mathrm{Cr}^{3+/} \mathrm{Cr}^{6+}\right]$ and $\left[\mathrm{As}^{3+1} \mathrm{As}^{5+}\right]$ in Crude Oil and Asphaltene Derivative Using Hyphenated Liquid Chromatography and Plasma Quadrupole Mass Spectrometry. Canadian Journal of Pure and Applied Sciences, 9, 3613-3620.

[7] Elhameed, A.A., Pillay, A.E., Nunn, R. and Stephen, S. (2015) Pollutant and Heavy Metal Retention in Asphaltenes: Environmental Implications? Canadian Journal of Pure and Applied Sciences, 9, 3567-3572.

[8] Salih, F.M., Pillay, A.E. and Jayasekara, K. (2008) Impact of Potential ${ }^{40} \mathrm{~K}$ Contamination of Aquatic Resources by Waste Water from Oil. Journal of Nutritional \& Environmental Medicine, 17, 178-183. http://dx.doi.org/10.1080/13590840802310118

[9] Al Taie, H., Pickersgill, J. and Al Taie, N. (1999) Oman: A Comprehensive Guide to the Sultanate of Oman. Al Roya Publishers, Muscat.

[10] Robinson, J.G. (1993) The Limits to Caring: Sustainable Living and the Loss to Biodiversity. Conservation Biology, 7, 20-28. http://dx.doi.org/10.1046/j.1523-1739.1993.07010020.x

[11] Williams, J.R. and Pillay, A.E. (2015) Heavy Metals and the Alternate Bearing Effect in the Date Palm (Phoenix dactilifera). Journal of Environmental Protection, 6, 995-1002. http://dx.doi.org/10.4236/jep.2015.69088

[12] Shearman, R. (1990) The Meaning and Ethics of Sustainability. Environmental Management, 14, 1-8. http://dx.doi.org/10.1007/BF02394014

[13] Speight, J.G. (2004) Asphaltenes, Resins and Structure of Petroleum. Oil and Gas Science Technology, 59, 467-477. http://dx.doi.org/10.2516/ogst:2004032 
[14] Spiecker, P.M., Gawrys, K.L. and Kilpatrick, P.K. (2003) Aggregation and Solubility Behavior of Asphaltenes and Their Subfractions. Journal of Colloid and Interface Science, 267, 178-193. http://dx.doi.org/10.1016/S0021-9797(03)00641-6

[15] Abbu, R., Pillay, A.E. and Moodley, K.G. (2000) The Use of ICP-AES and Anodic Stripping Voltammetry (ASV) to Determine the Levels of Cadmium and Lead in River Water Samples from Kwa Zulu-Natal (KZ-N), South Africa. Journal of Trace and Microprobe Techniques, 18, 83-97.

[16] Peisach, M., Pineda, C.A. and Pillay, A.E. (1994) PIXE Yield Enhancement of Metal Fluorides under Bombardment with Charged Particles. Journal of Radioanalytical and Nuclear Chemistry, 178, 387-397. http://dx.doi.org/10.1007/BF02039732

[17] Peisach, M., Pineda, C.A., Pillay, A.E. and Springhorn, K.A. (1994) Time Variation of Abnormal PIXE Yields from Some Insulating Binary Metal Fluorides under Proton Bombardment. Nuclear Instruments and Methods in Physics Research, 94, 540-544. http://dx.doi.org/10.1016/0168-583X(94)95434-8

[18] Pillay, A.E., Williams, J.R., Hassan, S.M., and Al-Hamdi, A. (2005) Boron and the Alternate-Bearing Phenomenon in the Fard Cultivar of the Gulf. Journal of Arid Environments, 62, 199-207. http://dx.doi.org/10.1016/j.jaridenv.2004.11.007

[19] Williams, J.R., Pillay, A.E., Hassan, S.M., El Mardi, M.O. and Al-Hamdi, A. (2005) Levels of Selected Metals in the Fard Cultivar (Date Palm). Journal of Arid Environments, 62, 211-225. http://dx.doi.org/10.1016/j.jaridenv.2004.04.005

[20] Pillay, A.E. and Peisach, M. (1992) Some Studies on Nuclear Methods for Boron Determination. Nuclear Instruments and Methods in Physics Research Section B: Beam Interactions with Materials and Atoms, B66, 226-229. http://dx.doi.org/10.1016/0168-583X(92)96155-R

[21] Punyadeera, C., Pillay, A.E., Jacobson, L. and Whitelaw, G. (1997) Application of XRF and Correspondence Analysis to Provenance Studies of Coastal and Inland Archaeological Pottery from the Mngeni River Area, South Africa. $X$-Ray Spectrometry, 26, 249-256. http://dx.doi.org/10.1002/(SICI)1097-4539(199709)26:5<249::AID-XRS188>3.0.CO;2-5

[22] Pillay, A.E., Elkadi, M., Stephen, S., Manuel, J. and Khan, M.Z. (2013) Potential Environmental Effects Linked to Elemental Toxicity of Neem Biodiesel and Alternative Fuels (B20/B100). Canadian Journal of Pure and Applied Science, 7, 2397-2403. 